\title{
Retrospective Study of Conservative Management of Appendicular Lump
}

\author{
Adhikari B
}

\begin{abstract}
Introduction: Appendicitis is very common surgical emergency and incidence of appendicular lump is about 2-6\%.There are different approaches for management of appendicular lump among which most common and widely accepted approach is managing lump conservatively with interval appendicectomy 6 weeks after resolution of inflammation. The aim of the study is to evaluate the efficacy of the conservative management in appendicular lump. Materials and methods: Retrospective study of the 43 patients admitted with a diagnosis of appendicular lump from March 2015 to February 2016 at Nepalgunj medical college, Nepalgunj were carried out. Result: Out of 204 patients of appendicitis 43(21.07\%) patients were found to have appendicular lump. Age ranged from 6 to $81 y$ rs old. Appendicitis was found to be common at the age range of 21 to 30 years (44.18\%).patient reported after 3 to 8 days of Onset of symptoms but most of the patients reported at 5 to 6 days of onset of symptoms. Among 43 patients, 40 patients (93.01\%) managed successfully with conservative management. Only three patients $(6.97 \%)$ developed complications. Out of these conservatively managed, 18(41.86\%) underwent interval appendicectomy, 19(44.18\%) patients lost to follow up,3(6.97\%) had recurrent appendicitis. Conclusion: Our study concluded that most of the appendicular lumps can be managed conservatively with few complications, which can be managed with immediate intervention.
\end{abstract}

Key words: Appendicular lump, appendicitis, interval appendicectomy

\section{INTRODUCTION}

Appendicitis is very common surgical emergency in surgical practice.Among most common sequel e being appendicular lump accounts for about $2-6 \%$ of the patients ${ }^{1,2}$. due to self defence mechanism of the body to localize the infection with in the lump formed by inflamed appendix,omentum,caecum and terminal ileum ${ }^{1}$.Well accepted treatment strategy of appendicular lump is conservative regimen followed by interval appendicectomy after 6weeks following resolution of all the symptoms ${ }^{3}$.

Lump formation are more common in extreme of ages (children and old ages) ${ }^{4}$. Futhermore appendicular lump can have complications like appendicular perforations,abscess formation,gangrene of appendix and sometime gangrene of caecum.In the management of appendicular lump three general approach has been employed ${ }^{5,6}$. Clasical and most accepted approach among the surgeons is conservative management till the inflammation subsides usually taking 6 weeks then going for interval appendicectomy so that the surgery is less hazardous,easy as all the inflammation and adhesions has already been subsided and has very less chance of lifethreatening complications like faecal fistula ${ }^{7-9}$. Semi conservative approach involves immediate appendicectomy after resolution of inflammatory process in few days after initial admission and third approach is to manage entirely with

\footnotetext{
Address for correspondence:

Dr. Bimarsh Adhikari

Department of Surgery

Nepalgunj Medical College Teaching Hospital

Nepalgunj, Banke, Nepal

Email: bimarsha10@gmail.com
}

conservative approach and interval appendicectomy only when patient has recurrent attack of appendicitis.

As there are many approaches most common and widely accepted approach is first one that is managing lump conservatively and going for interval appendicectomy after 6 weeks which helps to avoid recurrence of appendicitis and misdiagnosis mostly in females ${ }^{10-13}$.

The study was conducted to evaluate the outcome of the patients of appendicular lump managed by most acceptable approach ie managing conservatively for about 6 weeks then going for interval appendicectomy after resolution of all the inflammatory process.

\section{MATERIAL AND METHODS}

A retrospective study was conducted at Nepalgunj medical college hospital, Nepalgunj from March 2015 to February 2016, all the patients of all the age managed conservatively for appendicular lump were considered.The diagnosis of the appendicular lump was done with clinical evaluation which was confirmed further by ultrasound abdomen. All the patients considered were managed conservatively by Ochsner Sherren regime and further going for interval appendicectomy after 6 weeks. The study included data regarding demographics, symptoms duration, stay at hospital, complications, recurrence, rate of elective appendicectomies and follow ups. All the data were analyzed with SPSS software.

\section{RESULTS}

Total number of patients presenting with feature of appendicitis were 204. 43(21.07\%) were diagnosed as appendicular lump who were managed conservatively. Age 
range varied from 6 to 81 years (Table I). Out of total 43 patients $28(65.11 \%)$ were male and $15(34.88)$ were female with a ratio of 1.8:1.The time taken for the presentation to the hospital after the onset of symptoms were ranged from 2 to 8 days but the maximum number (41.86\%) of patients presented between 5-6 days (Table II). Among 43 patients, 40 patients (93.01\%) managed successfully with conservative management. Only three patients (6.97\%) developed complications in the form of an appendicular abscess among which 2 were managed with USG guided aspiration and one needed laparotomy. All the patient recovered well. Out of these conservatively managed, $18(41.86 \%)$ underwent interval appendicectomy after 6 weeks interval, $19(44.18 \%)$ patients lost to follow up, 3(6.97\%) had recurrent appendicitis. all of them underwent emergency appendicectomy.

\begin{tabular}{|c|c|c|}
\hline Age Group & $\begin{array}{c}\text { Number of } \\
\text { patients }\end{array}$ & $\%$ \\
\hline $1-10$ & 3 & 6.97 \\
\hline $11-20$ & 7 & 16.27 \\
\hline $21-30$ & 19 & 44.18 \\
\hline $31-40$ & 5 & 11.62 \\
\hline $41-50$ & 3 & 6.97 \\
\hline $51-60$ & 3 & 6.97 \\
\hline $61-70$ & 1 & 2.32 \\
\hline $71-80$ & 1 & 2.32 \\
\hline $81-90$ & 1 & 2.32 \\
\hline Total & 43 & 100 \\
\hline
\end{tabular}

Table I: Age distribution

\begin{tabular}{|c|c|c|}
\hline $\begin{array}{c}\text { Duration of } \\
\text { symptoms }\end{array}$ & $\begin{array}{c}\text { Number of } \\
\text { patients }\end{array}$ & Incidence $\%$ \\
\hline$<72$ hours & 5 & $11.62 \%$ \\
\hline $4-5$ days & 11 & $25.58 \%$ \\
\hline $5-6$ days & 18 & $41.86 \%$ \\
\hline$>6$ days & 9 & $20.93 \%$ \\
\hline
\end{tabular}

Table II: Duration of symptoms at presentation

\section{DISCUSSION}

Appendicitis is very common surgical emergency in. If patient doesn't present hospital early ie with in 24 to 48 hours the body tries to localize the infection by forming lump or mass ${ }^{14}$.

In our study the incidence of appendicular lump was $21.07 \%$ where as its about $2-6 \%$ in other similar study ${ }^{1,2}$. The higher incidence can be due to late presentation to the hospital and lack of knowledge about the disease and its consequences. Financial problem could be the other reason. The maximum number of the patient in this study group were between the age group of 21 to 30 years which shows that appendicitis is common in young age group which is similar to other studies though it can occur in any age group. The male to female ratio was 1.86:1 with a male predominance which is similar to other studies. Majority of the patient presented 5-6 days after the onset of symptoms, which is a late presentation than in other similar studies, reason behind could be the above mention factors ${ }^{15}$.

The success rate of conservative management of appendicular lump was $90.02 \%$ ( 40 out of 43 ) which is comparable with other studies $^{16}$. There were no mortality among conservatively managed as well as those requiring intervention for complications.

3(6.97\%) patient developed appendicular abscess which was managed successfully, two requiring USG guided aspiration and one of them needed laparotomy with appendicectomy post operative period was uneventful. In similar studies failure of conservative management is about $2-3 \%$ of the cases with emergency exploration ${ }^{17}$. Similarly $3(6.97 \%)$ patient came with recurrent appendicitis and were successfully managed with emergency appendicectomy. 18 patients (41.86\%) followed up in the duration of the study period of one year and underwent interval appendicectomy remaining 19 patients (44.18\%) lost the follow up.

\section{CONCLUSIONS}

Most of the cases of appendicular lump can be managed conservatively but needs strict observation and regular clinical examination of the patient to timely identify complications like abscess formation or perforations and if identified they should be managed immediately.

\section{REFERENCES}

1. Jordan JS, Kovalcik PJ, Schwab CW. Appendicitis with palpable mass. Ann Surg. 1981; 193(2):227-9.

2. Arnbjornsson E. Managementof Appendiceal Abscess. Curr Surg. 1984;41:4-9

3. D.E. Deakin, I Ahmed. Interval appendicectomy after resolution of adult inflammatory appendixis it necessary surgeon 2007; 1:45-50.

4. Kumar S, Jain S. Treatment of appendiceal mass: prospective, randomized clinical trial. Indian J Gastroenterol. 2004; 23:165-7.

5. Willemsen PJ, Hoorntje LE, Eddes EH, Ploeg RJ, The need for interval appendectomy after resolution of an appendiceal mass questioned. Digestive surgery.2002; 19:216-22.

6. Ein SH, Langer JC, Daneman A, Nonoperative management of pediatric ruptured appendix with inflammatory mass or abscess: presence of an appendicolith predicts recurrent appendicitis, Journal of pediatric surgery.2005; 40: 1612-5.

7. Brown CV, Abrishami M, Muller M, Velmahos GC, Appendiceal abscess: immediate operation or percutaneous drainage?, The American Surgeon.2003; 69: (2003) 829.

8. Friedell ML, Perez-Izquierdo $M$, Is there a role for interval appendectomy in the management of acute appendicitis?, The American surgeon.2000;66: 1158-62.

9. Tekin A, Kurtoğlu HC, Can I, Öztan S, Routine interval appendectomy is unnecessary after conservative treatment of 
appendiceal mass, Colorectal Disease.2008; 10: 465-8.

10. Eryilmaz R, Sahin M, Savaş MR, [Is interval appendectomy necessary after conservative treatment of appendiceal masses?], Ulusal travma ve acil cerrahi dergisi= Turkish journal of trauma \& emergency surgery: 2004; 10: 185-8.

11. Bagi P, Dueholm S, Nonoperative management of the ultrasonically evaluated appendiceal mass, Surgery. 1987; 101: 602-5.

12. Samuel M, Hosie G, Holmes K, Prospective evaluation of nonsurgical versus surgical management of appendiceal mass, Journal of pediatric surgery.2002; 37: 882-6.

13. Adalla SA, Appendiceal mass: interval appendicectomy should not be the rule, The British journal of clinical practice. 1995; 50:168-9.

14. Ali S, Rafique HM, Appendicular mass; Early exploration vs conservative management, Professional Med J. 2010 17: (2010)180-4.

15. Pandey CP, Kesharwani RC, Chauhan CG, Pandey MK, Mittra P, Kumar P, Raza A, Management of appendicular lump: early exploration vs conservative management, International journal of medical science and public health. 2013;4:1046-9.

16. Bhandari RS, Thakur DK, Singh KP, Revisiting appendicular lump, Journal of Nepal Medical Association. $2010 ; 178$ : 108-11.

17. Malik AM, Shaikh NA, Recent trends in the treatment of the appendicular mass, INTECH Open Access Publisher; 2012. 